\title{
Captura de datos 3D para virtualizar el patrimonio cultural
}

3D data capture to virtualize cultural heritage

Recibido: agosto 30 de 2020 | Revisado: setiembre 12 de 20202 | Aceptado: octubre 02 de 2020

\author{
Norma LeÓn Lescano ${ }^{1}$ \\ YANN BARNET \\ Alvaro Racchumi Santillan ${ }^{3}$
}

1 Laboratorio de Software y Tecnologías Interactivas Universidad de San Martín de Porres, Perú

Correo:nleonl@usmp.pe

2 Instituto de Urbanismo y Construcción IVUC Universidad de San Martín de Porres, Lima Perú

3 Alvaro Racchumi Santillan

Laboratorio de Software y Tecnologías Interactivas

Universidad de San Martín de Porres, Lima Perú

\begin{abstract}
Resumen
El objetivo de este artículo es describir el método seguido para capturar datos 3D del patrimonio cultural del Palacio de Puruchuco, situado en el distrito de Ate en la ciudad de Lima (Perú). El proceso incluye la captura de datos gráficos $3 \mathrm{~d}$ usando fotogrametría mediante drones y escaneo $3 \mathrm{~d}$, optimización de los modelos 3D obtenidos para su posterior integración en ambientes navegables con realidad virtual.
\end{abstract}

Palabras clave: fotogrametría, escaneo $3 \mathrm{~d}$, patrimonio cultural, realidad virtual

\begin{abstract}
The objective of this article is to describe the method for 3D data capture of virtual heritage of Puruchuco Palace, located in the district of Ate in the city of Lima, Peru. The process includes the capturing $3 \mathrm{D}$ graphics data using photogrammetry with drones and a 3D data scanning, 3D model optimization and integration for navigable environments with virtual reality..
\end{abstract}

Key words: photogrammetry, 3d scanning, virtual reality cultural heritage

\footnotetext{
(C) Los autores. Este artículo es publicado por la Revista Campus de la Facultad de Ingeniería y Arquitectura de la Universidad de San Martín de Porres. Este artículo se distribuye en los términos de la Licencia Creative Commons Atribución No-comercial - Compartir-Igual 4.0 Internacional (https://creativecommons.org/licenses/ CC-BY), que permite el uso no comercial, distribución y reproducción en cualquier medio siempre que la obra original sea debidamente citada. Para uso comercial contactar a: revistacampus@usmp.pe.
} 


\section{Introducción}

El Perú tiene un amplio y trascendente patrimonio arqueológico; sin embargo, debido al paso demoledor de la historia (Monge, 2017) nutrida de calamidades naturales, construcción no planificada, falta de recursos para la conservación entre otros riesgos (Ministerio de Cultura, 2017) muchos de los sitios arqueológicos se han dañado y en el peor de los casos han desaparecido definitivamente. Una manera de enfrentarse a esta problemática es el uso de tecnologías de fotogrametría para generar gemelos 3D del patrimonio que son utilizados luego, tanto para su conservación como para su valorización gracias a herramientas de virtualización e interfaces 3D (Poupyrev, Kruijff, La Viola, \& McMahamn, 2017).

Este artículo describe los procesos para generar una réplica virtual del Palacio de Puruchuco (Figura1), un edificio patrimonial restaurado, insertado en un área arqueológica del distrito de Ate, Lima, Perú (Figura 2) sometido a la presión urbana de las poblaciones que lo rodean (Figura 3). Se exponen los métodos, herramientas y tecnologías usadas con la visión de ponerlos a disposición de profesionales e investigadores del patrimonio cultural.

El Palacio de Puruchuco está ubicado en la base de un cerro y fue residencia del Curaca, quien era la máxima autoridad local Inca, (Tavera, 2020). Es un edificio restaurado con ambientes cerrados, las paredes son de adobe y tapial, sus techos son horizontales y están revestidos de una torta de barro (Villacorta, Vetter, \& Ausejo, 2003). Por su ubicación contra laderas, alta complejidad arquitectónica, pasajes muy angostos, espacios cubiertos y la homogeneidad de su textura de tierra, este edificio patrimonial presenta varios desafíos en cuanto a su levantamiento por fotogrametría, lo que fue determinante para su elección como caso de estudio.

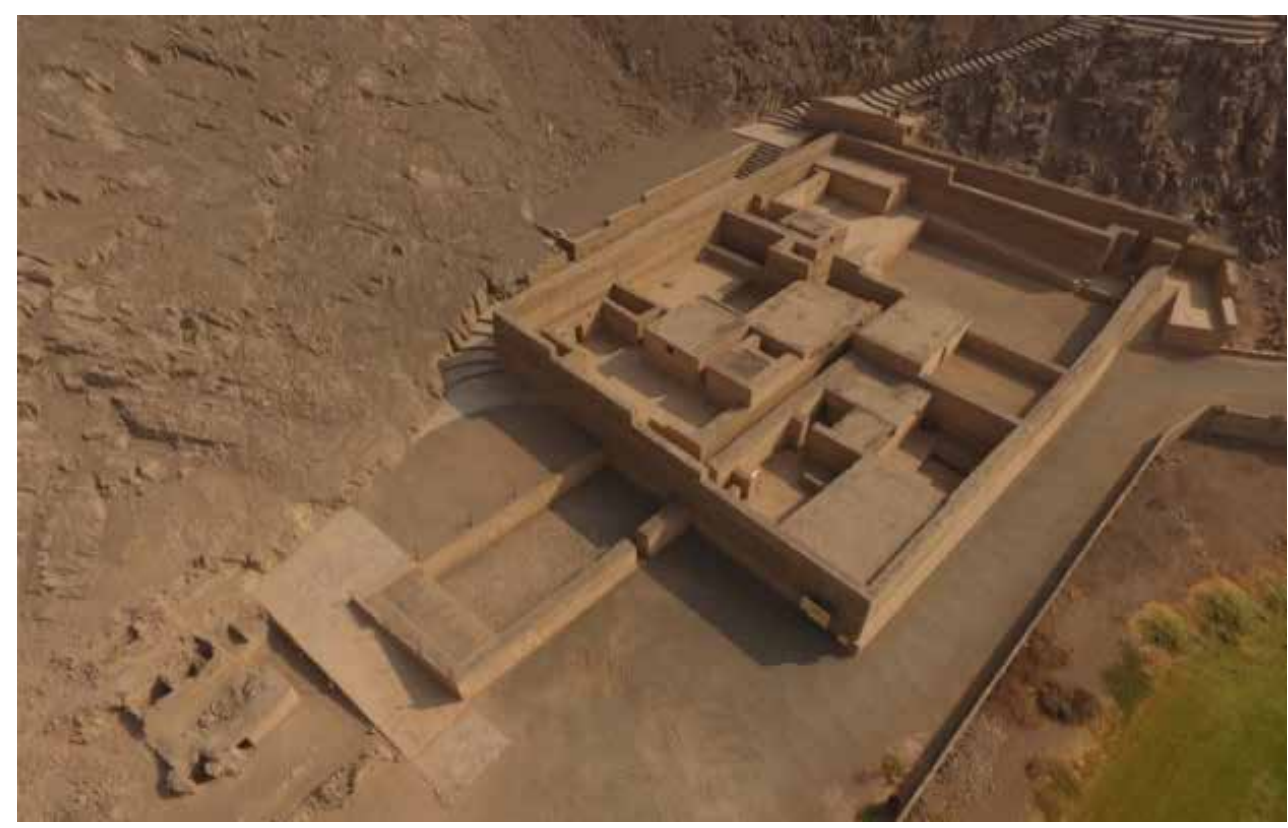

Figura 1. Palacio de Puruchuco fotografiado con drone 


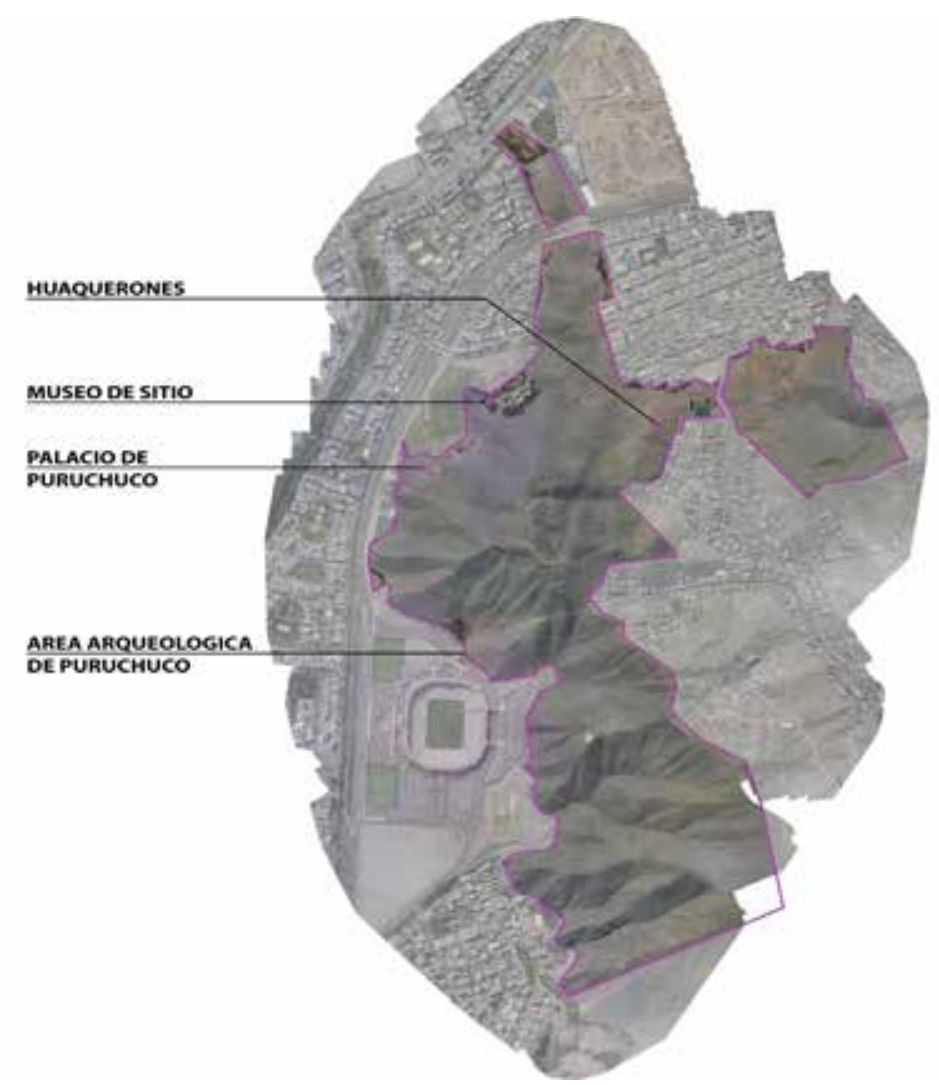

Figura 2. Ortofoto del área Arqueológica de Puruchuco generada con PIX4D

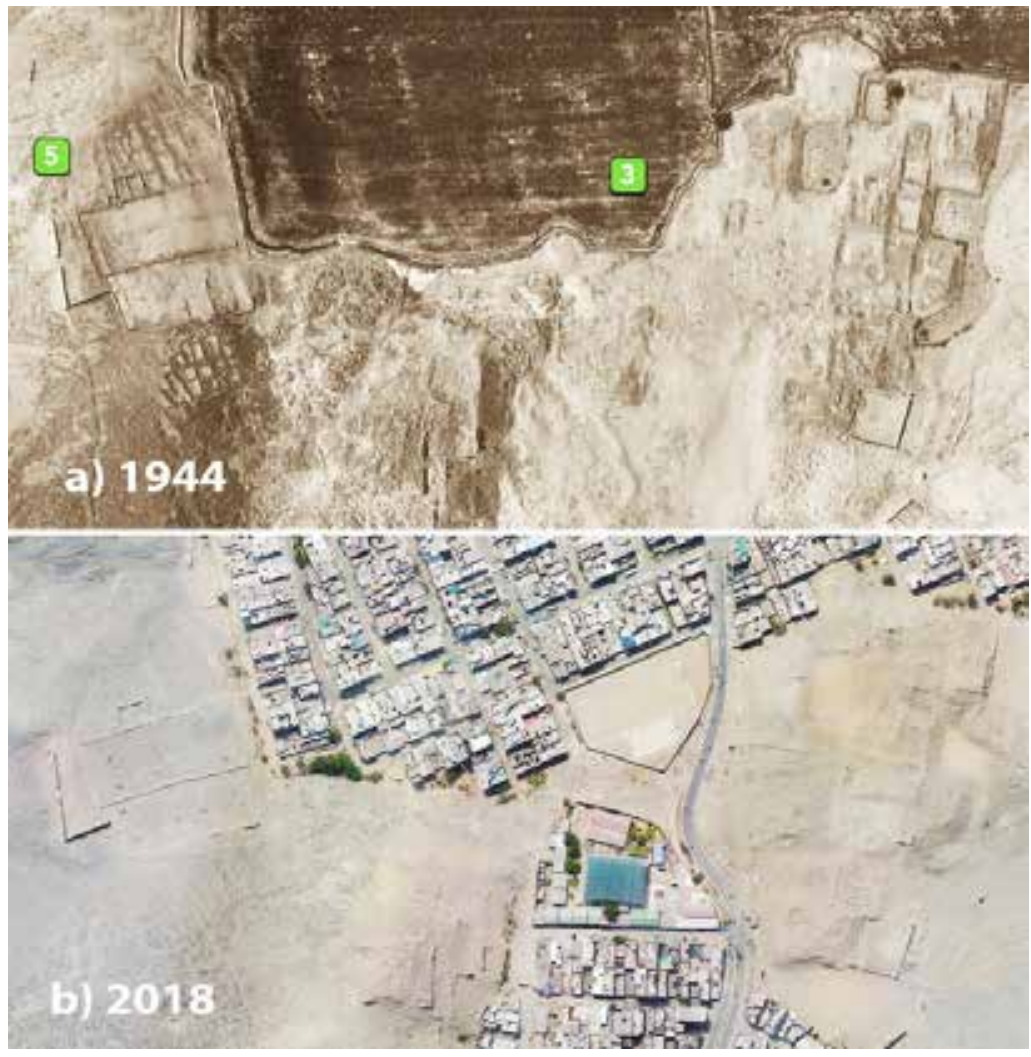

Figura 3. Invasiones urbanas consolidándose en la zona arqueológica de Huaquerones 


\section{Método}

El objetivo de la investigación es describir y analizar los procesos que se emplearon para generar un modelo 3D del Palacio Puruchuco que se pueda utilizar luego en la creación de ambientes virtuales navegables. El método aplicado tiene cuatro fases como se muestra en la Figura 4: Adquisición de datos 3D de la parte exterior, Adquisición de datos 3D de ambientes interiores, Optimización de los modelos, Integración 3D de los modelos.

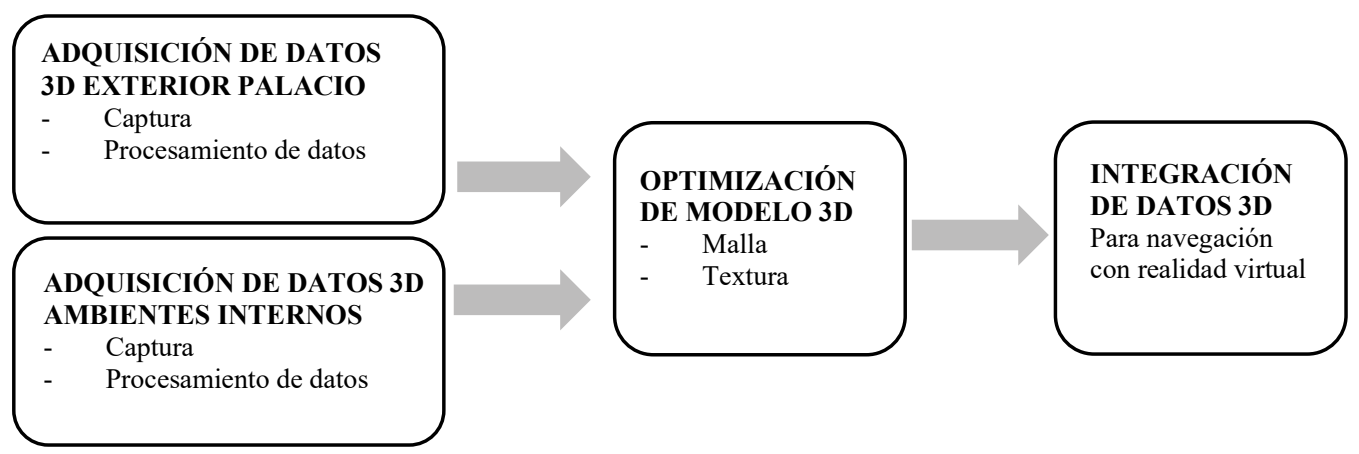

Figura 4. Proceso de virtualización del patrimonio cultural

Para cada una de esas fases, se describe los procesos seguidos, las herramientas utilizadas, las variables analizadas y los resultados cualitativos o cuantitativos obtenidos. Luego, se sintetiza esta información en un método para la virtualización del patrimonio arqueológico inmobiliario que indica los parámetros óptimos identificados y los tiempos de ejecución con las herramientas y tecnologías empleadas.

\section{Herramientas y tecnologías}

La captura de data 3D para virtualizar el patrimonio requiere el uso de tecnologías, métodos y herramientas de toma masiva de información, cuyo nivel de sofisticación debe ser escogido en función a los objetivos específicos del proyecto (Barrera-Vera, 2008). Los métodos basados en la fotogrametría que permiten la creación de una nube de puntos del objeto levantado se pueden basar en cámaras fotográficas sencillas, o equipamientos de alta tecnología y alta precisión gracias a sistemas láser. Ambos son válidos: a mayor tecnología, mayores costos de equipamiento, y a menor tecnología, mayor cantidad de trabajo (Maiellaro, Varasano, \& Capotorto, 2018).

Dentro de una visión de conservación y popularización masiva del patrimonio cultural, se privilegió soluciones tecnológicas de bajo costo. Por lo tanto, se optó por la fotogrametría basada en fotografías tomadas por un UAV (drone equipado de una cámara) para levantar las partes exteriores del Palacio y su entorno inmediato (Tabla 1). Sin embargo, para los ambientes internos del Palacio, cuya luminosidad es muy baja, se empleó tecnologías de uso la tecnología de captura de imágenes HDR y datos de profundidad mediante la cámara insignia de Matterport (Tabla 2).

Ambas técnicas permiten la generación de una nube de puntos que se puede convertir en una malla $3 \mathrm{D}$ con 
textura. No se utilizó láser 3D para la parte externa porque es una herramienta muy costosa y demandaría un tiempo mucho mayor de captura comparado a la solución con UAV. Además, por el nivel de precisión requerido, no se justificaba esta opción.

En ambos casos, las mallas 3D generadas fueron optimizadas con un software de edición 3D, buscando corregir eventuales anomalías, y sobre todo para disminuir la complejidad y el peso del modelo 3D (Tabla 3).

La integración de los modelos 3D se llevó a cabo en el software Unity (Tabla 4). Este programa permite importar los modelos 3D en escenas distintas y crear objetos interactivos que las conectan entre sí. De esa manera, se crea un espacio virtual integrado de fácil manejo y con tiempos de ejecución óptimos (Unity Technologies, 2016).

Tabla 1

Equipo y software empleados para adquisición y procesamiento de data $3 D$ mediante UAV

Procesos
Recolección de información
previa
Colocación puntos de control -
Servicio de topografía
Planes de vuelo

Captura Fotográfica

Procesamiento de las fotografías para generar un modelo 3D

\section{Equipos y software empleados}

Google Earth, cinta métrica, cámara sencilla

Receptor GNSS (Marca trimble, modelo R7 GNSS)

Software Pix4D Capture, de libre de uso, compatible con el modelo de drone empleado.

\section{Tablet iPad Mini 4}

Drone DJI Phantom 4. UAV común de gama intermedia con buena relación costo/calidad (Costales, 2018). Características: 1. autonomía de vuelo efectiva: $20 \mathrm{~min}$; 2. Cámara FOV $94^{\circ} 20 \mathrm{~mm}(35 \mathrm{~mm}$ format equivalent) $\mathrm{f} / 2.8$ focus at $\infty$, def $3000 \times 4000$ pixeles; 3 . Sistema de auto estabilización; 4. GPS.

Software PIX4D Mapper. Escogido por estudios comparativos con otros softwares similares en los cuales destaca su precisión, calidad de ortofoto que es importante para generar texturas y velocidad de procesamiento (Costales, 2018), así como referencias de proyectos similares de levantamiento de edificios patrimoniales (Pix4D SA, 2020).

PC Pentium 7 con 32 GB de RAM, tarjeta video nvidia 32 GB.

Tabla 2

Equipo y software empleados para adquisición y procesamiento de data 3D mediante Laser3D

\begin{tabular}{lll}
\hline Procesos & Equipos y software empleados \\
\hline Captura de la data 3D & Cámara Matterport Pro sobre pie. \\
$\begin{array}{l}\text { Procesamiento de la data para } \\
\text { generar nube de punto y malla 3D }\end{array}$ & $\begin{array}{l}\text { Plataforma Matterport, software CORTEX AI (red neuronal de } \\
\text { aprendizaje profundo que crea datos espaciales 3D). }\end{array}$ \\
\hline
\end{tabular}

Tabla 3

Equipo y software empleados para optimización del modelo

\begin{tabular}{ll}
\hline Procesos & Equipos y software empleados \\
\hline Optimización de la malla 3D & Blender, software gratuito \\
& PC Pentium 7 con 32 GB de RAM, tarjeta video nvidia 32 GB. \\
$\begin{array}{ll}\text { Optimización y retoque de las } \\
\text { texturas }\end{array}$ & $\begin{array}{l}\text { Adobe Photoshop } \\
\text { PC Pentium 7 con 32 GB de RAM, tarjeta video nvidia 32 GB. }\end{array}$ \\
\hline
\end{tabular}


Tabla 4

Equipo y software empleados para integración de los modelos

\begin{tabular}{ll}
\hline Procesos & Equipos y software empleados \\
\hline Integración de los modelos & Unity versión 2019.2.21f. \\
& PC Pentium 7 con 16 GB de RAM, tarjeta video 4 GB. \\
\hline
\end{tabular}

\section{Resultados}

Captura de datos 3D de la parte externa del Palacio

Para capturar el conjunto del Palacio y su entorno inmediato se optó por la técnica de menor costo: la fotogrametría basada en la captura de fotos con UAV. Sin embargo, para no abandonar una precisión razonable del levantamiento, ya que se deseaba conservar los datos para ser explotados en futuros estudios, se buscó volar de la forma más cercana posible al Palacio y así obtener la definición máxima que puede ofrecer el equipo. El método permite generar una nube de puntos utilizando los pixeles de fotografías georreferenciadas y el proceso tiene las siguientes etapas:

a. Adquisición de información previa

Esta etapa permite definir estrategias eficientes de trabajo de campo. En primer lugar, se define las coordenadas aproximadas del perímetro del área de levantamiento utilizando data existente: planos topográficos, puntos georreferenciados, información de Google Earth o simplemente data proporcionada por el software de planificación de vuelo.

En segundo lugar, es esencial conocer las alturas aproximadas de los elementos por levantar, utilizando planos existentes, o mediciones en campo. En tercer lugar, se estudia el entorno del área por levantar, sobre todo para identificar posibles elementos que obstaculicen el vuelo del drone o escondan partes de patrimonio como postes, cables, carteles, señaléticas, otras edificaciones etc. Como el Palacio de Puruchuco está situado contra una ladera muy espinada, se buscó la altura de la zona más alta de la zona de vuelo (Tabla 5). Con esa información se determinó que la altura mínima de vuelo era de $15 \mathrm{~m}$ desde la parte más baja. Para finalizar, se gestionó con la administración del sitio para obtener las autorizaciones de vuelo y agendarlos en momentos oportunos en los cuales no hay público.

Tabla 5

Características del área por capturar del Palacio Puruchuco

\begin{tabular}{ccccc}
\cline { 2 - 5 } & Ancho & largo & \multicolumn{2}{c}{ Altura elemento más alto } \\
Pared & Terreno \\
\hline Área Palacio & $45 \mathrm{~m}$ & $85 \mathrm{~m}$ & $10 \mathrm{~m}$ & $13 \mathrm{~m}$ \\
\hline
\end{tabular}

\section{b. Colocación de puntos de control}

Para garantizar la precisión de la geolocalización y geometría del modelo, se colocaron cuatro puntos de control georreferenciados en el área perimétrica del Palacio.

\section{c. Planes de vuelo}

Definir las alturas de los vuelos 
es un elemento clave porque la precisión del modelo y de su textura está asociado a la definición de los pixeles, que dependen directamente de la resolución de la cámara y de la distancia hacia el sujeto. Es posible estimar el GSD ("ground sample distance") que representa la distancia en el suelo que separa los centros de dos píxeles adyacentes de la fotografía aérea (suele darse en $\mathrm{cm}$ o $\mathrm{mm}$ ). Con la cámara del Drone Phantom 4, el vuelo más bajo a 15 metros de altura del sujeto ofrece un GSD referencial de $0.67 \mathrm{~cm}$ con un ángulo casi vertical, y un GSD referencial de $0.93 \mathrm{~cm}$ con un ángulo a $45^{\circ}$. Eso significa que se puede esperar alcanzar como máximo una definición de un pixel por un centímetro en nuestra textura.

La altura de vuelo determina también la cantidad de foto por hacer y por consecuencia el tiempo de vuelo necesario. Para realizar modelos 3D de edificaciones, la documentación técnica recomienda que se realicen vuelos tipo cuadrícula doble (fotografías en dos ejes y cuatro direcciones) con traslapes altos: a lo menos $85 \%$ de traslape frontal y a lo menos 70\% de traslape lateral (Pix4D SA, 2020). El software permite estimar los tiempos de vuelo y la cantidad de fotos en función de la altura y del traslape deseado. Para el área del Palacio de próximamente 4400 metros cuadrados, se pudo realizar un vuelo completo con un traslape superiores a $80 \%$ utilizando la casi totalidad de la capacidad de la batería (Figura 5). Para áreas superiores, se tendría que planificar varios vuelos. Se exploró la posibilidad de complementar la captura de data con vuelos circulares alrededor del Palacio con la intención de sacar una mejor imagen de los muros perimetrales. No dio buenos resultados, debido a las grandes diferencias que presentaban los GSD entre las fotografías.

Luego, se requiere configurar la inclinación de la cámara. Para levantar edificios, se recomienda una inclinación de $45^{\circ}$ (mayor inclinación posible con la serie Phantom de DJI). Otro vuelo con una inclinación de $70^{\circ}$ (más vertical) lo puede complementar (Pix4D SA, 2020).

En el estudio, se comparó resultados entre vuelos a $45^{\circ}, 60^{\circ}$ y $80^{\circ}$. Optamos por utilizar el ángulo de $80^{\circ}$ (la posición más vertical posible en la planificación de vuelo) porqué el Palacio cuenta con corredores muy estrechos flanqueados de paredes muy altas cuyo fondo solo es visible en una posición vertical de cámara. También se combinaron entre ellos, obteniendo los siguientes resultados:

La inclinación de $45^{\circ}$ sola es la que $\mathrm{da}$ los mejores resultados en cuanto a texturas, ya que permite el mejor registro de las partes verticales. Sin embargo, presenta mayor cantidad de anomalías en la nube de puntos, comparado a vuelos más verticales. Combinar vuelos de $45^{\circ}$ con $80^{\circ}$ permite mejorar ligeramente la calidad de la geometría y reducir las anomalías, pero no se nota una mejora en la calidad de la textura. Obviamente, por trabajar con muchas más fotografías, los tiempos de proceso se vuelven mucho más largos ( Tabla 6). 


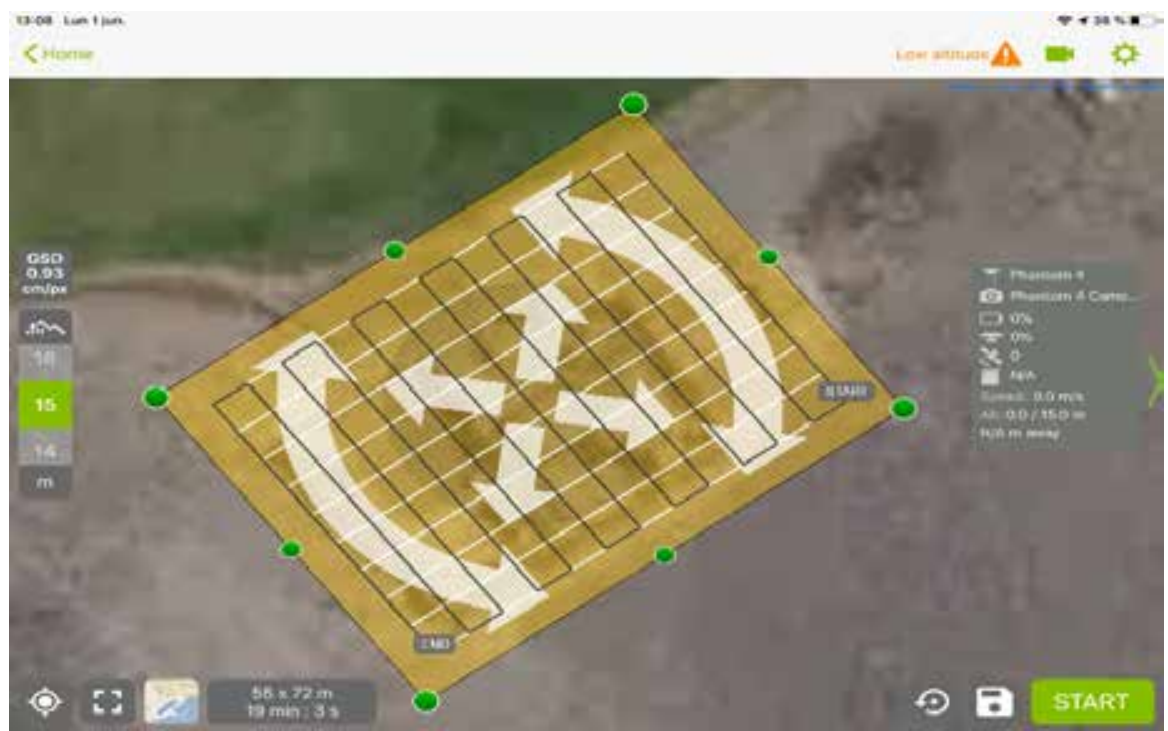

Figura 5. Planificación de vuelo Doble cuadrícula con Pix4D Captur

Tabla 6

Características de los vuelos

\begin{tabular}{llccc}
\hline $\begin{array}{l}\text { Tipo recorrido/ } \\
\text { Área }\end{array}$ & Altura & Ángulos cámara & $\begin{array}{l}\text { Traslape } \\
\text { Frontal /lateral }\end{array}$ & Cantidad fotos \\
\hline Cuadricula doble & \multicolumn{2}{l}{ Medio día soleado - Lapso de tiempo de 45min } \\
\hline $4640 \mathrm{~m}^{2}$ & $15 \mathrm{~m}$ & $45^{\circ}$ & $84 / 84$ & 616 \\
$5800 \mathrm{~m}^{2}$ & $17 \mathrm{~m}$ & $80^{\circ}$ & $80 / 80$ & 418 \\
Cuadricula doble & Medio día nublado - Lapso de tiempo de 60 min & \\
$4500 \mathrm{~m}^{2}$ & $15 \mathrm{~m}$ & $45^{\circ}$ & $80 / 80$ & 288 \\
$5000 \mathrm{~m}^{2}$ & $20 \mathrm{~m}$ & $80^{\circ}$ & $85 / 85$ & 259 \\
\hline
\end{tabular}

\section{d. Captura fotográfica}

La iluminación, y en particular las sombras, tienen un papel clave en la adquisición de fotografías. Para evaluar las mejores condiciones de luz, se realizaron vuelos con sol despejado inclinado (tarde), con sol despejado vertical (medio día) y con tiempo nublado (medio día). Si bien la presencia del sol ofreció una buena calidad y tonalidad de imagen, ideal para realizar un video de recorrido virtual realista y ameno, trajo una serie de inconvenientes para el propósito de crear modelos 3D fidedignos y navegables. Aun en posición vertical de mediodía, el sol crea contrastes marcados con zonas de sombra intensa que resultan muy difícil de analizar con la fotogrametría. Genera anomalías geométricas y falta de data para la malla y las texturas.

En la Figura 6, las partes blancas muestran la carencia de puntos en la nube, especialmente en las zonas oscuras. Este problema se reduce significativamente en el modelo generado con fotografías tomadas un día nublado. Además, las sombras cambian rápidamente en el tiempo, lo que limita mucho la duración y cantidad de vuelos que se pueden realizar.

En la Figura 7, se visualiza las franjas de sombra en la textura de un modelo generado a partir de dos vuelos que 
se realizaron en un transcurso de solo $45 \mathrm{~min}$. Ese inconveniente descarta las condiciones soleadas en casos de patrimonio que demande varios vuelos, a menos que se hagan de forma simultánea con varios drones, lo que demanda recursos adicionales. Por otro lado, tener una iluminación claramente definida por el sol, descarta las posibilidades de crear un modelo navegable en el cual se pueda escoger o variar la iluminación de forma artificial, lo que puede resultar muy importante para simular y estudiar la iluminación de ciertos momentos claves en culturas precolombinas.

Por lo tanto, para los objetivos del proyecto, se recomienda realizar vuelos con una luz que sea la más difusa e intensa a la vez, un día nublado a medio día ("la panza de burro de Lima"), confirmando conclusiones de otro trabajo de modelización de patrimonio con fotogrametría realizado sobre iglesias (Duguleana \& Postelnicu, 2018)

Finalmente, es importante definir en modo fijo la regulación de luz de la cámara. Si se deja en automático, se corre el riesgo de que la cámara cambie de modo en función de la dirección de la toma y que se genere fotografías con diferentes tonos de color e iluminación, afectando la generación de la nube de punto y afectando la textura del modelo.

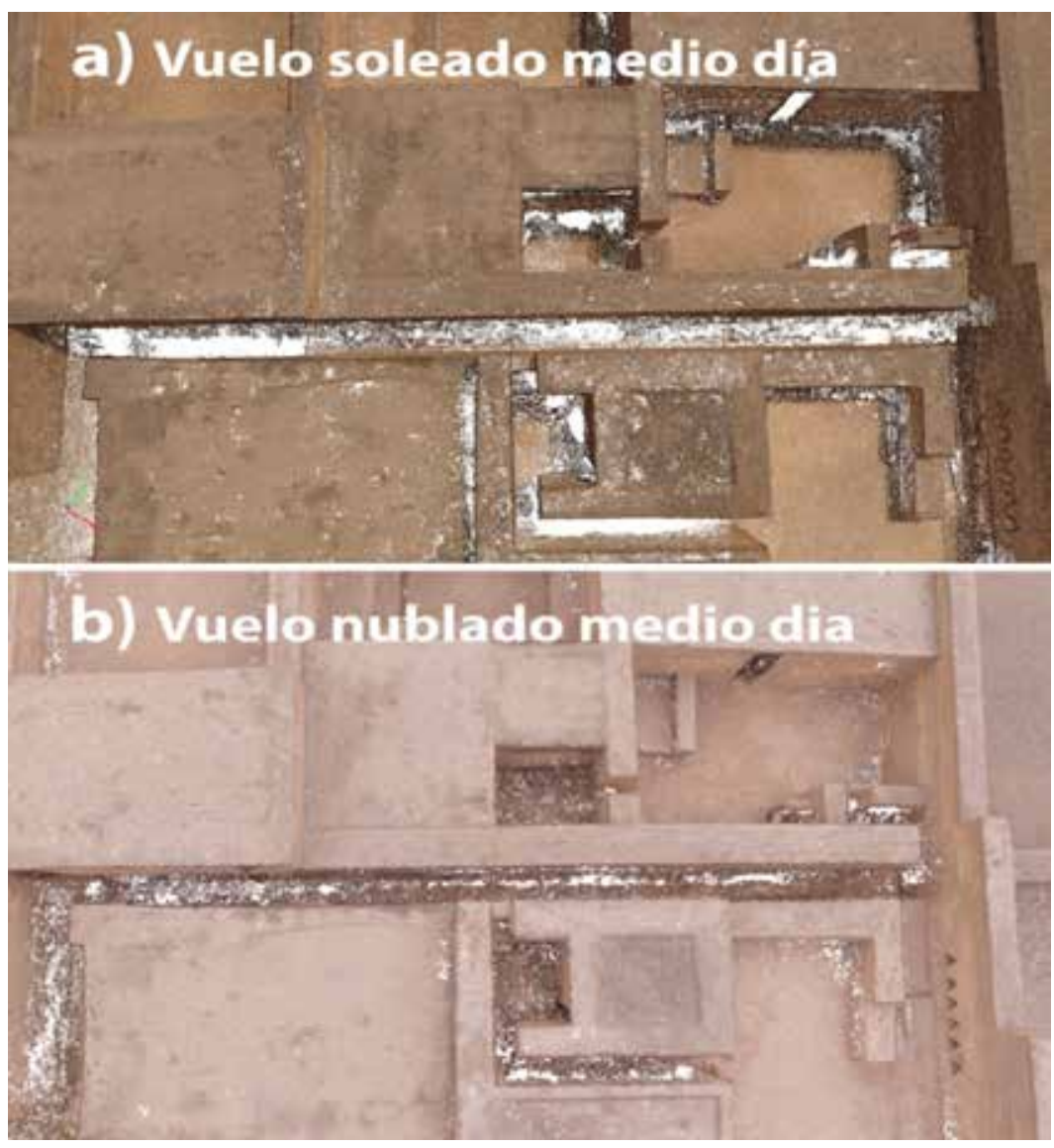

Figura 6. Comparación de calidad de la nube de puntos en función a las condiciones de luz - Las zonas blancas en las imágenes enseñan la ausencia de puntos. 


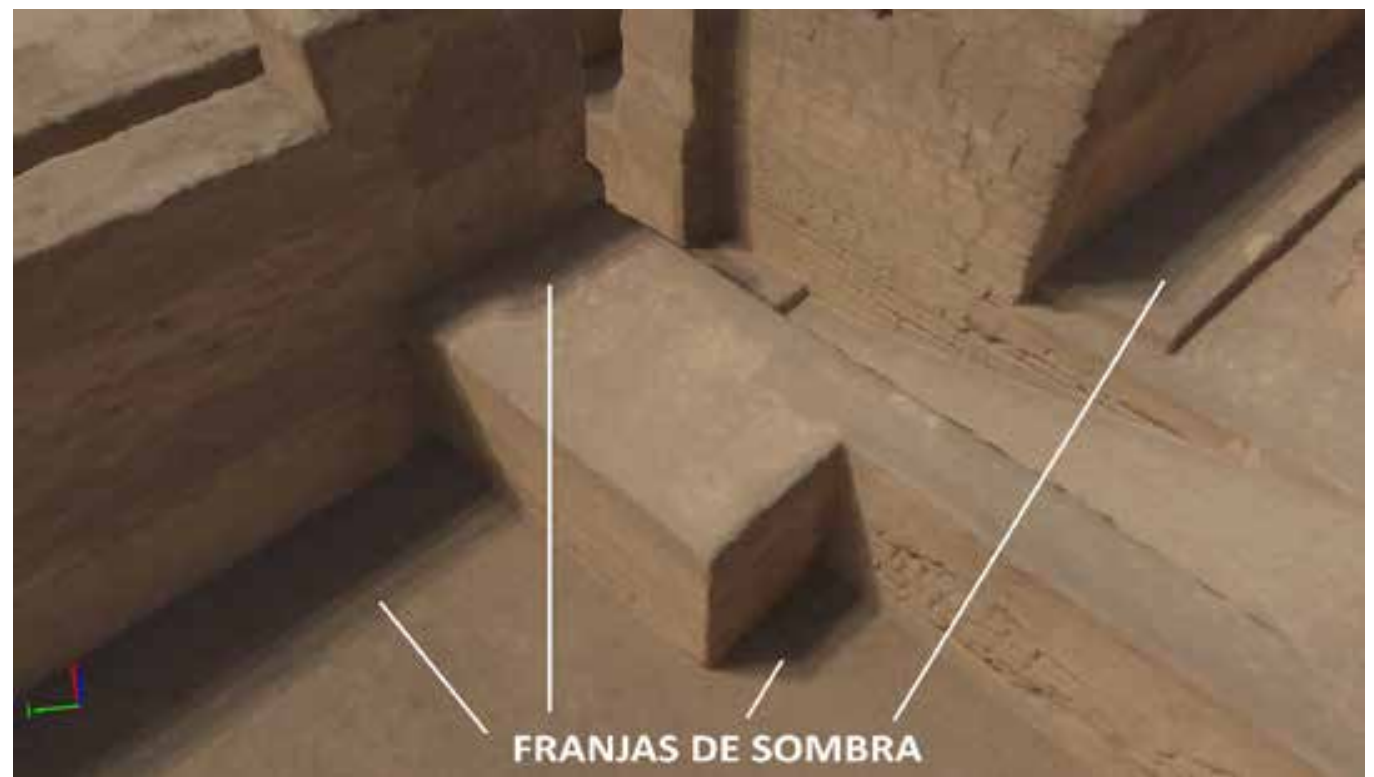

Figura 7. Problema de franjas de sombra en la textura. Modelo realizado en base a fotos capturadas por dos vuelos realizados a medio día en un lapso de solo $45 \mathrm{~min}$.

\section{Procesamiento de las fotografias obtenida por el UAV}

El procesamiento para generar un modelo desde las fotografías con el software Pix4DMapper se realiza en cinco (05) etapas:

a. Proceso inicial: se crea una nube de punto inicial y una pre-calibración de las cámaras con las fotografías capturadas.

b. Ingreso de puntos de control: se ingresan los datos de los puntos de control y se ubica su posicionamiento de forma manual sobre las fotografías. Este proceso lleva a una re-calibración definitiva de las cámaras. También se puede delimitar la zona de procesamiento durante esta etapa (Figura 8).

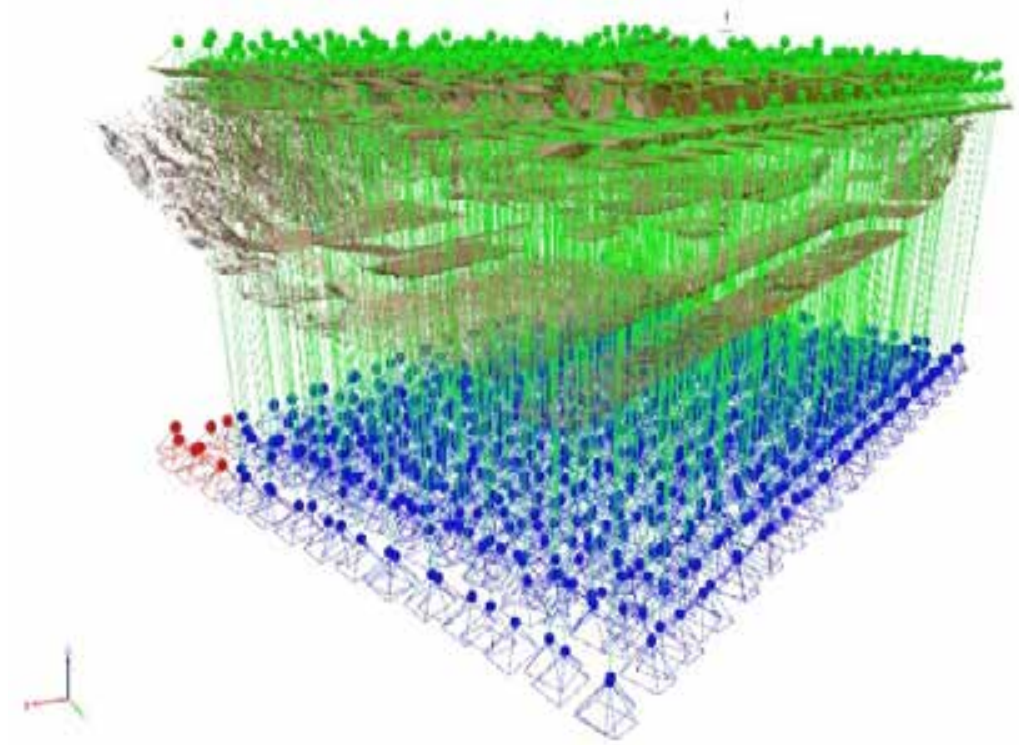

Figura 8. Recalibración de las fotografías después la introducción de los puntos de control 


\section{c. Creación de la nube de puntos del} modelo: Es la etapa que demanda más tiempo y recursos de cómputo. El software ofrece varias opciones que tienen un impacto importante sobre los tiempos de procesamientos (cantidad de pixeles analizados por imagen, número mínimo de correspondencia para generar un punto y densidad de puntos por generar. Los resultados obtenidos utilizando las imágenes en su máxima definición no han ofrecido una diferencia cualitativa significativa con la opción que utiliza $50 \%$ de las imágenes. Aumentar la cantidad mínima de correspondencias para crear un punto, tampoco genero una mejora de la nube de puntos, al contrario, se obtuvo mayor cantidad de anomalías. En cuanto a la densidad de puntos, se optó por la opción más densa y lenta, ya que tiene un impacto importante sobre la calidad máxima de la textura que se puede obtener luego.

d. Limpieza de la nube de puntos: Es un proceso manual que consiste en seleccionary deshabilitar los puntos que presentan anomalías en la geometría del modelo y elementos no deseables, como paneles de información y barandas. En nuestro caso ver número 4 en la Figura 9 . Puede ser una etapa muy laboriosa, sobre todo si la captura de fotografía no ha sido óptima.

En el caso de Puruchuco, se generaron tres grandes tipos de anomalías (Tabla 7). En la Figura 9, los puntos con color representan los datos deshabilitados manualmente: el número 1 corresponde a geometrías fantasmas por falta de traslape en puntos muy altos; el número 2 corresponde a "puntos voladores", típicos de las fotografías a $45^{\circ}$, especialmente, en las intersecciones entre los planos verticales y horizontales de las paredes; el número 3 corresponde a errores por falta de precisión e información en zonas oscuras.

En los dos primeros casos, la limpieza es relativamente sencilla y permite general una geometría fidedigna. En el último caso, el problema es mucho más complejo ya que eliminar puntos mal ubicados significa perder data y continuidad en la malla por generar. La única solución es tratar de resolver esas anomalías luego, manipulando directamente la malla en el proceso de optimización del modelo 3D.

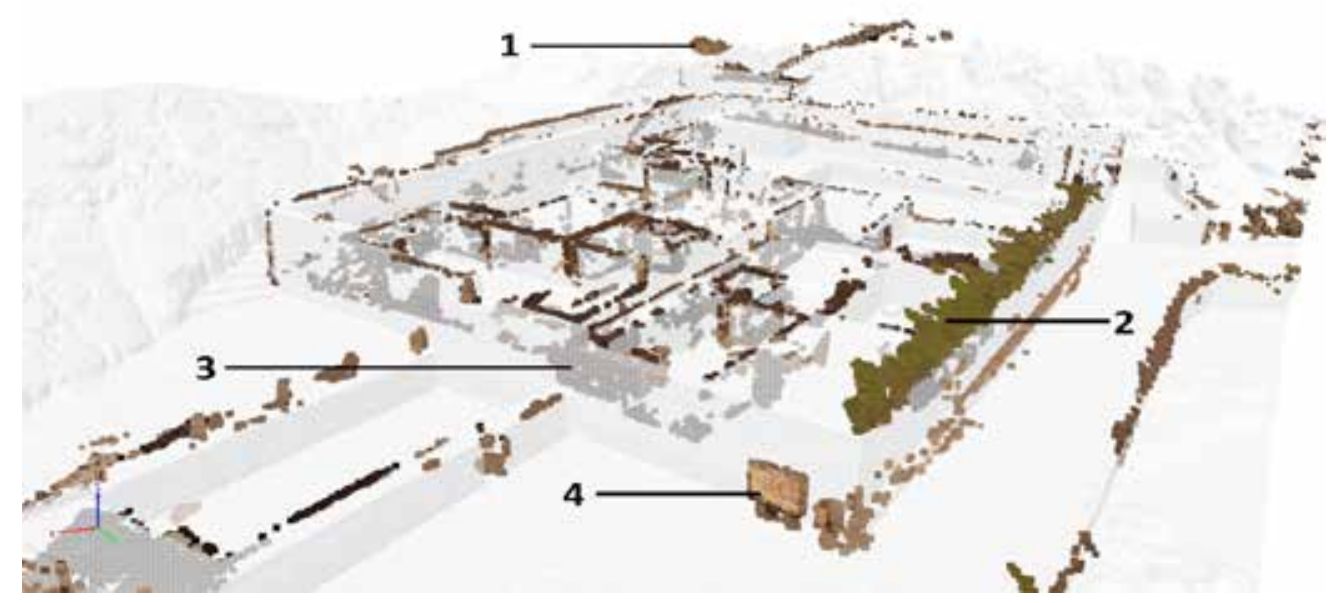

Figura 9. Proceso de limpieza de la nube de puntos - Captura de pantalla de Pix4D Mapper 
Tabla 7

Anomalias

\begin{tabular}{ll}
\hline Anomalías & Características \\
$\begin{array}{l}\text { Generación de geometrías } \\
\text { "fantasmas" }\end{array}$ & $\begin{array}{l}\text { En las zonas más altas del modelo en la cual el drone se encontraba a una } \\
\text { distancia muy reducida del objeto (menos de 2 metros en unos lugares), } \\
\text { lo que reduce drásticamente el nivel de traslape entre las fotografías } \\
\text { Sucede en las junciones entre la parte vertical y horizontal de las paredes. } \\
\text { (el hecho que todo el Palacio tenga la misma tonalidad y textura dificulta } \\
\text { "voladores", }\end{array}$ \\
$\begin{array}{l}\text { Errores y falta de precisión } \\
\text { en las zonas obscuras }\end{array}$ & Pasillos profundos y angostos y zonas con mucha sombra \\
\hline
\end{tabular}

e. Generación de una malla de triángulos con su textura: En base a la nube de punto depurada, el software permite generar una malla de triángulos (exportable en formato .obj o .fbx ) (Figura 10) y una imagen de textura asociada en formato .jpg con distinto nivel de definición que implica también grandes diferencias en el tiempo de procesamiento. Los productos generados están detallados en la Tabla 8.

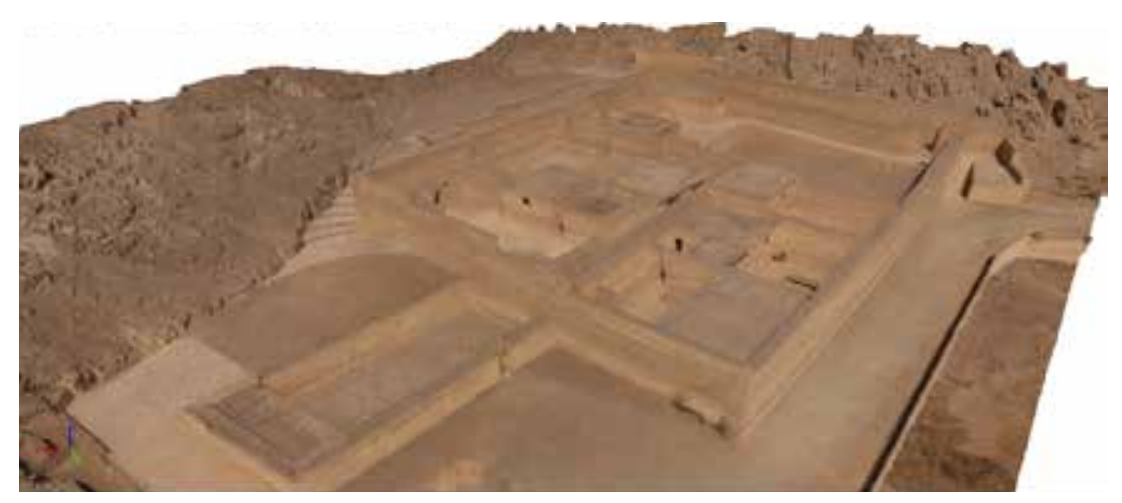

Figura 10. Malla con textura generada a partir de la nube de puntos - Captura de pantalla de Pix4D Mapper

Tabla 8

Productos generados con Pix4D Mapper

\begin{tabular}{ccccc}
\hline & Malla 3D & \multicolumn{2}{c}{ Textura .jpg } \\
\hline Formato & $\begin{array}{c}\text { Cantidad de triángulos } \\
\text { (caras) }\end{array}$ & Peso(mega) & Dimensiones (pixeles) & Peso (mega) \\
. obj & 999999 & 67.3 & $8192 \times 8192$ & 13.0 \\
.$f b x$ & 999999 & 41.3 & $8192 \times 8192$ & 14.1 \\
.$f b x$ & 4999999 & 167.5 & $16384 \times 16384$ & 45.3 \\
\hline
\end{tabular}

En base a la malla generada con mejor definición se evaluó a que distancia la textura era de suficiente calidad para una visualización satisfactoria con una pantalla de 1280x720 pixeles. En la Figura 11, se muestra superficies a distintas distancias del observador: el número 1 , con distancia inferior a $8 \mathrm{~m}$, la calidad de la textura es insuficiente; el número dos, con distancia de $9 \mathrm{~m}$, la calidad es ligeramente insuficiente, el número 3, a 12 metros de distancia, la visualización se vuelve satisfactoria; y el número 4 , a $18 \mathrm{~m}$ de distancia, la calidad de la textura es muy satisfactoria. 


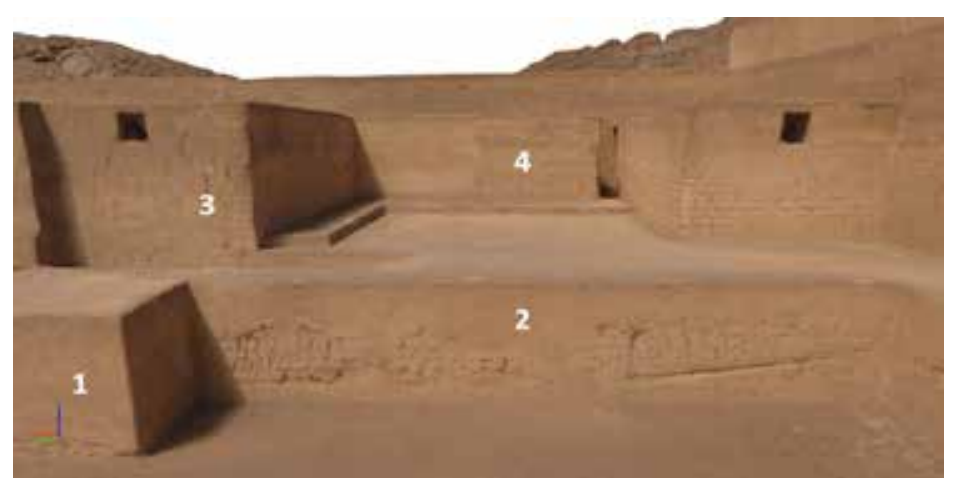

Figura 11. Nivel de calidad de visualización de texturas según distancia entre el observador y el objeto. 1. 8m: calidad insuficiente, 2. 9m: Calidad ligeramente insuficiente $3.12 \mathrm{~m}$ : calidad satisfactoria $4.18 \mathrm{~m}$ : calidad muy satisfactoria. Captura pantalla Pix4D

\section{Adquisición de datos 3D de ambientes internos del Palacio de Puruchuco}

Se usó la tecnología de captura de imágenes HDR y datos de profundidad mediante la cámara insignia de Matterport que gira automáticamente sobre un pie. Para capturar la información 3D de ambientes internos, incorpora CORTEX AI, una red neuronal de aprendizaje profundo que crea datos espaciales $3 \mathrm{D}$ robustos, a partir del procesamiento avanzado de imagen, corrección de color automática, etiquetado de objetos y habitaciones entre otras funcionalidades que permite de manera consistente y precisa la creación un gemelo digital (Matterport, 2020) del espacio levantado.
Esta tecnología permitió obtener una copia digital fidedigna (Bentley, 2019) de los interiores del Palacio de manera muy rápida: un mediodía para tres espacios. A pesar de la poca iluminación natural de esos ambientes, se logró una malla 3D y una textura de alta precisión y calidad, como se muestra en la Figura 12. Por cada modelo, se generó ocho texturas en promedio. Este método puede escalar y convertirse en una herramienta para fortalecer las relaciones entre el modelo digital y el mundo real, fortaleciendo la conservación preventiva del lugar patrimonial (Jouan \& Hallot, 2019). Los productos generados para la digitalización de los tres ambientes se detallan en la Tabla 9.

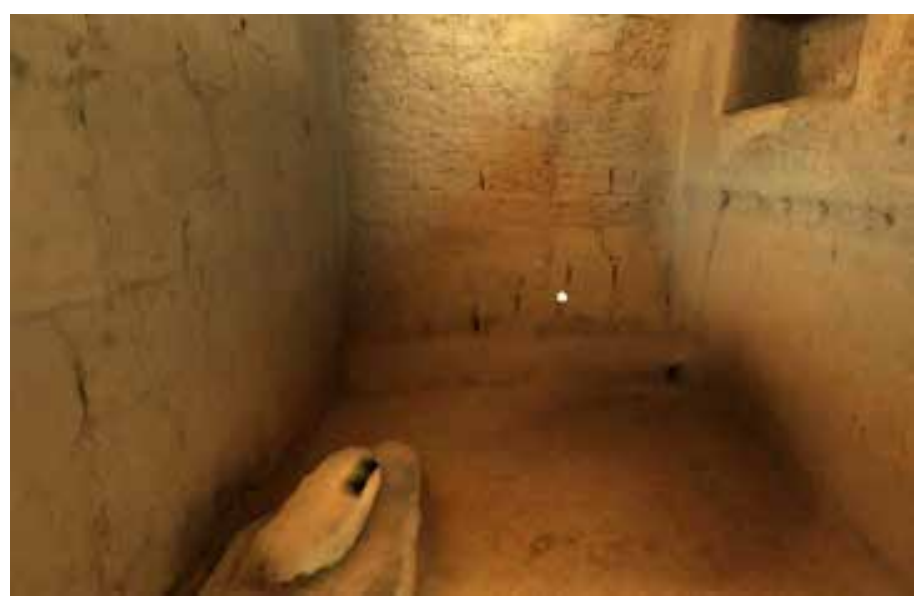

Figura 12. Modelo 3D de ambiente interno del Palacio de Puruchuco generado con la tecnología Matterport. 
Tabla 9

Productos generados con la plataforma Matterport platform

\begin{tabular}{lcccc}
\hline \multirow{2}{*}{ Ambientes } & \multicolumn{2}{c}{ Malla 3D. obj } & \multicolumn{2}{c}{ Textura .jpg } \\
\cline { 2 - 5 } & $\begin{array}{c}\text { Cantidad de } \\
\text { triángulos (caras) }\end{array}$ & Peso (mega) & Dimensiones (pixeles) & Peso(mega) \\
Deposito & 140,000 & $14 \mathrm{MB}$ & $2048 \times 2048$ cada textura & Rango de 1.0 a $1.2 \mathrm{MB}$ \\
Área de actividad & 101,394 & $14 \mathrm{MB}$ & $2048 \times 2048$ cada textura & Rango de $1.1-1.2 \mathrm{MB}$ \\
Cocina & 79,442 & $12 \mathrm{MB}$ & $2048 \times 2048$ cada textura & Rango de $1-1.5 \mathrm{MB}$ \\
\hline
\end{tabular}

\section{Optimización de los modelos 3D}

Los modelos 3D fueron optimizados, tanto las mallas como sus texturas para luego ser integrados en un espacio de realidad virtual.

a. Optimización de malla 3D: $\mathrm{La}$ optimización de las mallas $3 \mathrm{D}$ se realizó con el software de edición Blender. Se aplicaron los siguientes modificadores:

- "Smooth" (Suavisar), para aplanar y/o corregir los polígonos salientes en el modelo, mejorando la geometría. Se aplicó el factor de intensidad del suavizado en nivel Máximo y se configuró que este proceso se repitiera tantas veces como la malla lo necesite.

- "Decimate" y "collapse" (diezmar y colapsar), para reducir la cantidad de polígonos de la integralidad del modelo, conservando lo mejor posible su geometría. Este modificador redujo la cantidad de polígonos de la malla por próximamente la mitad.

- Se eliminó de forma manual los polígonos sobrantes en algunas partes de las mallas, como los planos horizontales (caminos exteriores y techos) donde abundaban vértices inútiles. Este proceso fue bastante tedioso, pero permitió simplificar esas superficies.

En el caso del modelo de la parte exterior del Palacio, se generó una malla optimizada con solamente 448792 polígonos de los 999999 que tenía el original Finalmente, se exporta el modelo optimizado en formato. fbx que resultado menos pesado que el formato .obj. Se aplicó el mismo método a las mallas de los modelos de los ambientes internos. La única excepción fue la malla del depósito, que tenía más polígonos protuberantes que los otros. Por lo tanto, el proceso de colapso se redujo a 0.2 en vez de 0.5 para no deteriorar los detalles de la geometría, $\mathrm{y}$ se tuvo que realizar el proceso en porciones de la malla seleccionadas de forma manual.

En la Tabla 10, se detallan los productos generados tras el proceso de optimización. Se nota que los rendimientos de optimización de malla han sido mayores para los modelos obtenidos a través de la tecnología Matterport. Se puede explicar por dos factores: la mayor reducción de cantidad de polígonos que se logró obtener, por la menor complejidad geométrica de los ambientes internos, y el cambio de formato de .obj. a .fbx, que reduce significativamente el peso del archivo. 
Tabla 10

Optimización de las mallas $3 D$ con blender

\begin{tabular}{cccccc}
\hline Modelo 3D & $\begin{array}{c}\text { Cantidad de triangulos (caras) } \\
\text { original }\end{array}$ & optimizado & original & Peso (Mega) & $\begin{array}{c}\text { Rendimiento } \\
\text { optimizado } \\
\text { optimisación } \\
\text { de peso }\end{array}$ \\
\hline Palacio exterior & 999999 & 448792 & 41.3 (.fbx) & $21(. \mathrm{fbx})$ & $49 \%$ \\
Depósito & 140,000 & 21167 & 14 (.obj) & 1 (.fbx) & $93 \%$ \\
Área de actividad & 101,394 & 50697 & 14 (.obj) & $2.2(. \mathrm{fbx})$ & $84 \%$ \\
Cocina & 79,442 & 39721 & 12 (.obj) & 1.7 (.fbx) & $86 \%$ \\
\hline \multicolumn{7}{c}{ Promedio } & & $78 \%$ \\
\hline
\end{tabular}

\section{b. Optimización de textura}

En cuanto a la textura del modelo del Palacio exterior, se realizaron dos tipos de intervenciones con un editor de imagen: el retoque manual de la imagen para eliminar elementos parásitos (como carteles u objetos ajenos al edificio patrimonial) y guardar la imagen en formato JPG. con un mayor nivel de compactación y una menor definición, con el propósito de reducir su peso. La optimización del peso en megabytes y pixeles se muestra en la Tabla 11. En el caso de los modelos interiores, no se redujo el tamaño de las texturas porque no superaban dos (02) megas.

Tabla 11

Optimización de la textura

\begin{tabular}{cccc} 
Modelo 3D & $\begin{array}{c}\text { Peso Textura inicial (megas) } \\
\text { Cantidad de pixeles }\end{array}$ & $\begin{array}{c}\text { Peso textura optimizada } \\
\text { (megas) } \\
\text { Cantidad de pixeles }\end{array}$ & $\begin{array}{c}\text { Rendimiento } \\
\text { optimización de peso }\end{array}$ \\
Palacio exterior & $\begin{array}{c}14.1 \mathrm{Mb} \text {. } \\
8192 \times 8192 \text { pixeles }\end{array}$ & $4096 \times 4096$ pixeles & $57 \%$ \\
\hline
\end{tabular}

\section{c. Discusión sobre la optimización de modelo 3D}

La optimización de los modelos 3D depende de las interfaces con las que el usuario va a interactuar. El presente estudio buscó resultados óptimos para interfaces de usuario web y móvil, por lo que se redujo significativamente el peso final del modelo. En el caso del modelo exterior del Palacio, se logró que la suma de la malla $3 \mathrm{D}$ y de su textura no supere los 30 megas. Para lograrlo, se disminuyó por mitad la cantidad de sus polígonos y se redujo por la mitad la definición de la textura logrando un resultado final bastante satisfactorio, ya que no se visualiza una pérdida importante de calidad.
El proceso más tedioso fue la optimización de la malla 3D externa, debido a la dependencia de cuidado de la persona a cargo de esta tarea, que tiene que buscar el buen equilibrio entre simplificación y precisión de la geometría. En muchos casos se aplicó modificadores a partes específicas de la malla para asegurar la calidad del producto. Por otro lado, la optimización de los modelos internos fue realizada por la plataforma de inteligencia artificial y red neuronal de aprendizaje automático (Matterport, 2020) y tienen un peso promedio de 12 megas cada uno (incluyendo malla $y$ texturas) 


\section{Integración de datos}

Se integraron todos los modelos 3D optimizados en el software Unity, aplicando la estrategia de múltiples escenas con un modelo 3D en cada una. Para unirlos se creó un objeto intermedio de "Puerta", con el cual el usuario puede interactuar y le permite pasar de un ambiente a otro (Figura 14).

Se usó la compresión de texturas para acelerar los tiempos de carga, reducir la huella de memoria y obtener un rendimiento de renderizado óptimo. Las texturas fueron comprimidas de manera a utilizar una fracción del ancho de banda de memoria. A fin de optimizar aquellas texturas no comprimidas, se habilitó la opción de textura Mipmap, que permitir al GPU utilizar una resolución de textura menor para triángulos pequeños, esto limita la cantidad de datos de textura transferidos cuando el GPU está renderizando (Unity Technologies, 2019). El resultado se puede ver en las Figuras 13 y 14.

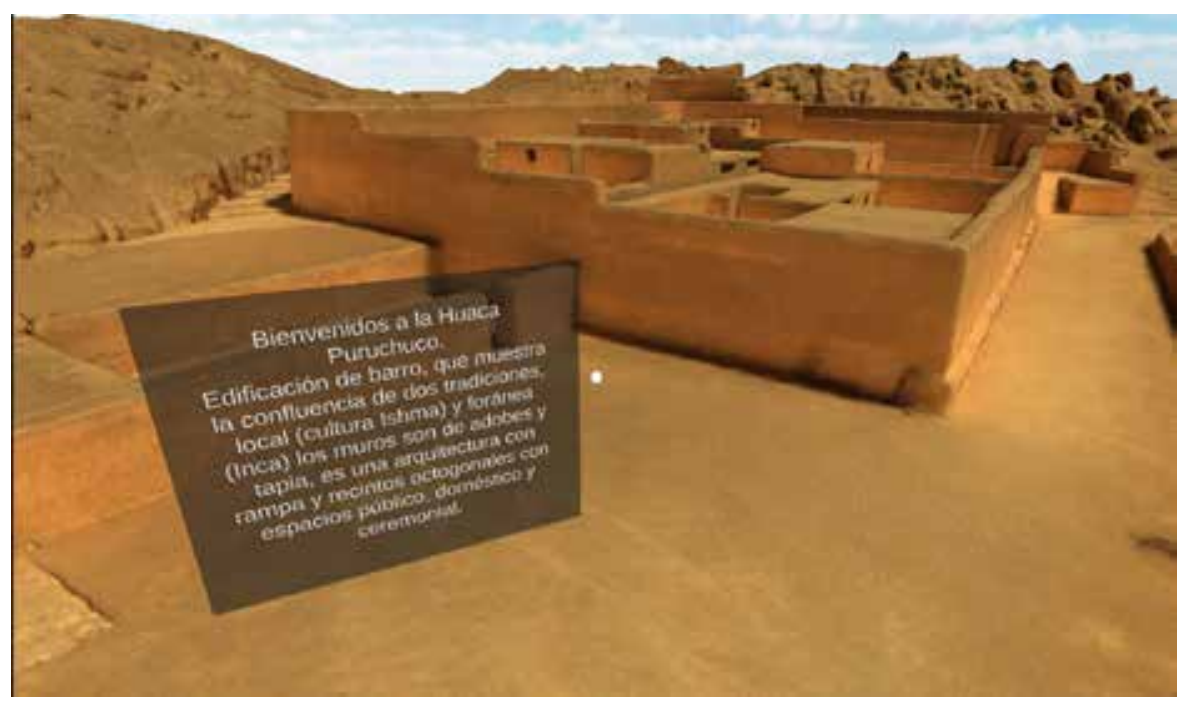

Figura 13. Modelo navegable integrado en UNITY

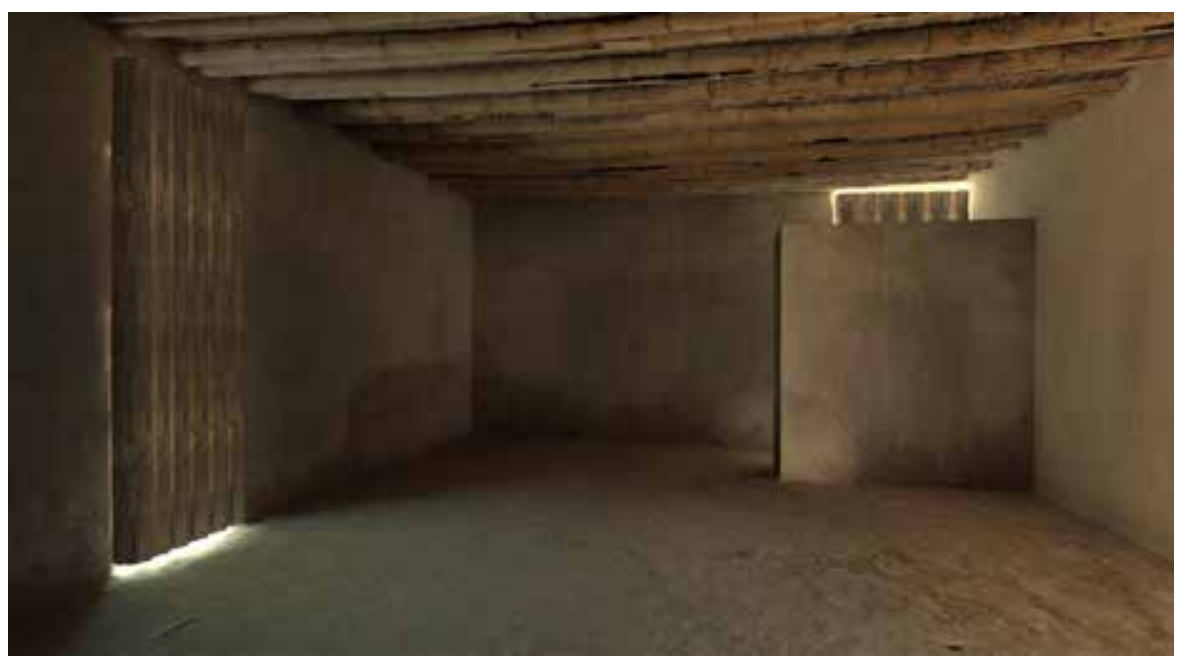

Figura 14. Modelo navegable integrado en UNITY. Se puede observar las puertas que permiten cambiar de escena e ingresar y salir de los ambientes internos. 


\section{Síntesis del método de virtualización}

Según los resultados obtenidos en función delas distintas variablesanalizadas tanto en la planificación de vuelo como en opciones de procesamiento, se generó un método con recomendaciones para una captura 3D óptima con los equipos y software empleados en este estudio. Las características del proceso y los tiempos de trabajo para una persona están expuestos en la Tabla 12.

Tabla 12

Resultado del método de virtualización del Palacio de Puruchuco con tiempos de trabajo

\begin{tabular}{|c|c|c|}
\hline Proceso & Características / Recomendación & Tiempo 1 persona \\
\hline $\begin{array}{l}\text { Levantamiento de } \\
\text { información previa }\end{array}$ & $\begin{array}{l}\text { Visita de campo para documentar las características del sujeto } \\
\text { y su contexto inmediato, recolección de información de } \\
\text { planimetría para delimitar el área y evaluar las alturas de vuelo } \\
\text { posible }\end{array}$ & 2 días \\
\hline $\begin{array}{l}\text { Colocación de puntos } \\
\text { de control }\end{array}$ & $\begin{array}{l}\text { Mínimo de } 3 \text { puntos. Para un área mayor de levantamiento, se } \\
\text { requiere más puntos }\end{array}$ & $\begin{array}{l}2 \text { días } \\
(1 \text { campo }+1 \\
\text { gabinete })\end{array}$ \\
\hline Planificación de vuelo & $\begin{array}{l}2 \text { vuelos tipo doble cuadricula con traslape frontal de } 85 \% \text { y } \\
\text { traslape lateral de } 80 \% \text { : } \\
1 \text { con cámara a } 45^{\circ} \text { y altura de vuelo entre } 10 \text { y } 20 \mathrm{~m} \\
1 \text { con cámara a } 70^{\circ} \text { (o } 80^{\circ} \text { si hay espacios muy encajonados) y } \\
\text { altura que permita un GSD similar al anterior }\end{array}$ & 1/2 día \\
\hline Vuelo & $\begin{array}{l}\text { Con asolamiento vertical y de preferencia nublado para bajar } \\
\text { los efectos de sombra muy contrastado }\end{array}$ & $1 / 2$ día \\
\hline $\begin{array}{l}\text { Procesamiento de la } \\
\text { nube de puntos }\end{array}$ & $\begin{array}{l}\text { Proceso inicial con definición completa } \\
\text { Colocación de los puntos de control y re calibración de cámaras } \\
\text { Generación de la nube de punto con una correspondencia } \\
\text { mínima de 3, } 50 \% \text { de la imagen y una densidad alta de puntos }\end{array}$ & $\begin{array}{l}1 \text { día } \\
\text { (5 horas de } \\
\text { procesamiento para } \\
\text { generar la nube) }\end{array}$ \\
\hline $\begin{array}{l}\text { Limpieza de la nube de } \\
\text { puntos }\end{array}$ & $\begin{array}{l}\text { Sectorizar el trabajo para no omitir zonas y evitar deshabilitar } \\
\text { puntos sin querer }\end{array}$ & 3 días \\
\hline $\begin{array}{l}\text { Generación de la malla } \\
\text { con su textura }\end{array}$ & $\begin{array}{l}\text { Malla de } 999999 \text { caras y textura de Alta resolución (mínimo } \\
8192 \text { x } 8192 \text { pixeles). Formato dxf. }\end{array}$ & 1 día \\
\hline $\begin{array}{l}\text { Captura y } \\
\text { procesamiento de data } \\
\text { con escáner 3D }\end{array}$ & $\begin{array}{l}\text { Seguir la metodología de la herramienta matterport, tratando } \\
\text { de disponer la cámara en lugares que permiten escanear la } \\
\text { integralidad del espacio. }\end{array}$ & $\begin{array}{l}1 / 2 \text { día } \\
\text { Para } 3 \text { ambientes de } \\
\text { menos de } 20 \mathrm{~m} 2\end{array}$ \\
\hline $\begin{array}{l}\text { Optimización de la } \\
\text { malla }\end{array}$ & $\begin{array}{l}\text { Aplicar modificadores Smooth (suavizar) la cantidad necesaria } \\
\text { de veces para alisar y simplificar la malla } \\
\text { Aplicar el modificador "Decimate" y "collapse" (diezmar } \\
\text { y colapsar). Tratar de disminuir por la mitad la cantidad de } \\
\text { polígonos } \\
\text { Editar de forma específica la malla en función a las características } \\
\text { propias del modelo. }\end{array}$ & 1 día \\
\hline $\begin{array}{l}\text { Optimización de la } \\
\text { textura }\end{array}$ & $\begin{array}{l}\text { Editar la textura manualmente para eliminar los elementos no } \\
\text { deseados. Disminuir la cantidad de pixeles a } 4096 \times 4096 \text {, y } \\
\text { aumentar el nivel de compactación Jpg. }\end{array}$ & $1 / 2$ día \\
\hline Integración en UNITY & $\begin{array}{l}\text { Integrar cada modelo generado en una escena separada y } \\
\text { conectarlos mediante un objeto interactivo de puerta que } \\
\text { permite al usuario pasar de una escena a la otra. }\end{array}$ & 1 día \\
\hline & TOTAL DE TIEMPO & 13 días \\
\hline
\end{tabular}




\section{Conclusiones}

En este artículo se ha explicado el método para levantar el modelo 3D del Palacio de Puruchuco con el propósito de generar la información para el proceso de virtualización del patrimonio cultural. La captura de datos de la parte exterior fue la que más dificultad presentó, tanto para la toma de fotos, así como para su procesamiento. Sin embargo, el uso de UAV como método de captura de fotografías para generar un modelo 3D navegable del conjunto del edificio patrimonial ha probado ser adecuado, debido a que la definición alcanzada supera las necesidades de virtualización del patrimonio, tomando en cuenta que la altura de vuelo permitió alcanzar un GSD inferior a $2 \mathrm{~cm}$. Con el equipo de UAV empleado, el área del Palacio de Puruchuco (entre 45000 y $50000 \mathrm{~m}^{2}$ ) es el límite superior para realizar 1 solo vuelo de capturas fotográficas con el nivel de detalle deseado.

A menos de hacer volar varios drones con la misma cámara de forma simultánea, recomendamos minimizar la cantidad de vuelos para evitar cambios de iluminación que afectan el proceso de fotogrametría y restitución de texturas uniformes. De hecho, las condiciones de luz tienen un impacto determinante sobre la calidad del producto generado, debiéndose privilegiar tomas con la mínima cantidad de sombras intensas. Sin embargo, es importante recalcar que el nivel de detalle alcanzado sirve para un trabajo de documentación patrimonial previo de ocurrencia media $( \pm 2 \mathrm{~cm})$.

Para una documentación detallada $( \pm 2 \mathrm{~mm})$ (Lettelier, 2007), se necesitaría realizar una captura de todo el conjunto con la técnica del escaneo 3D, la que se empleó para levantar los ambientes internos. En el caso del Palacio de Puruchuco, eso significaría generar modelos con decenas de millones de polígonos, demandando una capacidad que supera las características de las computadoras de escritorio más potente hoy en día. Con las capacidades tecnológicas actuales, resultó una buena decisión utilizar la tecnología de captura de imágenes HDR y datos de profundidad mediante la cámara insignia de Matterport para modelizar de forma separada los ambientes interiores cuya pequeña escala permite manejar una mayor definición.

En general, el proceso de optimización permitió reducir significativamente el peso de los archivos, logrando generar un modelo $3 \mathrm{D}$ de la parte exterior del Palacio de Puruchuco inferior a 30 megas. Por otro lado, el uso de escenas, compresión de texturas y la técnica del "mipmaping" facilitó la integración de todos los modelos asegurando una buena navegación con un renderizado óptimo. Con el método empleado, el proceso integral para llegar a la virtualización del Palacio de Puruchuco fue relativamente rápido: 13 días de trabajo de una persona desde el levantamiento de información previa hasta la integración de los modelos en un solo espacio virtual. 


\section{Referencias}

Barrera-Vera, J. (2008). Aplicaciones de tecnologías innovadoras en la documentación geométrica del Patrimonio Arquitectónico y Arqueológico. Sevilla: Universidad de Sevilla.

Barrera-Vera, J. (2008). Aplicaciones de tecnologias innovadoras en la documentación geométrica del Patrimonio Arquitectónico y Arqueológico. Sevilla: Sevilla University.

Bekelele, M., \& Champion, E. (2019). A comparison of Immersive Realities and Interaction Methods: Cultural Learning in Virtual Heritage. Frontiers in robotics and IA, 6-91.

Bentley. (2019). The Importance of Digital Twins for Resilient Infrastructure. Pennsylvania: Bentley.

Costales, G. (2018). Análisis comparativo entre los software de prueba Agisoft Photoscan y Pix4D para el procesamiento de datos obtenidos con fotogrametría de vehiculo aéreo no tripulado (UAV) de bajo costo aplicado a proyectos de medio ambiente. Quito: Escuela Politécnica Nacional.

Duguleana, M., \& Postelnicu, C. (2018). Towards Preserving Transylvanian Fortified Churches in Virtual Reality. International Conference on VR Technologies in Cultural Heritage. Springer, Cham.
Jouan, P., \& Hallot, P. (2019). Digital Twin: A Hbim-Based Methodology ToSupportPreventiveConservation Of Historic Assets Through Heritage Significance Awareness. The International Archives of the Photogrammetry, Remote Sensing and Spatial Information Sciences, XLII(2), 609-615.

Lettelier, R. (2007). Recording, documentation, and information management for the conservation of heritage places : guiding principles. Los Angeles: J. Paul Getty Trust.

Maiellaro, N., Varasano, A., \& Capotorto, S. (2018). Digital Data, Virtual Tours, and 3D Models Integration Using an Open-Source Platform. VRTCH 2018: VR Technologies in Cultural Heritage, 904, 148-164.

Matterport. (2020). Matterport . (Matterport Inc.) Recuperado el 11 de May de 2020, de https:// matterport.com/es/c\%C3\%B3mofunciona

Ministerio de Cultura. (2017). Paisajes Culturales en America Latina. Lima: Ministerio de Cultura.

Monge, J. (2017). Herramientas de difusión cultural en España. Catalunya: Universitat Oberta de Catalunya.

Pix4D SA. (2020). Pix4D Education. Recuperado el 05 de Abril de 2020, de https://www.pix4d.com/blog 
Pix4D SA. (2020). Pix4D Education. Recuperado el 05 de April de 2020, de https://www.pix4d.com/blog

Poupyrev, I., Kruijff, E., La Viola, J., \& McMahamn, R. (2017). 3D User Interfaces: Theory and Practice. Boston: Addison-Wesley.

Tavera, L. (29 de Septiembre de 2020). Sitios Arqueológicos. Obtenido de Puruchuco: https://www. arqueologiadelperu.com.ar/ puruchuco.htm

Unity Technologies. (2016). Multi Scene Editing. Obtenido de https://docs. unity3d.com/es/530/Manual/ MultiSceneEditing.html
Unity Technologies. (7 de Octubre de 2019). Optimizando el Rendimiento Gráfico. Obtenido de https://docs. unity3d.com/es/2018.4/Manual/ OptimizingGraphicsPerformance. html

Villacorta, L., Vetter, L., \& Ausejo, C. (2003). Puruchuco y la sociedad de Lima: Un homenaje a Arturo Jiménez Borja. Lima: Concytec. 